\title{
Fraud Crime Mitigation of Mobile Application Users for Online Transportation
}

\author{
https://doi.org/10.3991/ijim.v12i3.8070 \\ Amaya Andri Damaini $\left.{ }^{\varpi}\right)$, Ginanjar Setyo Nugroho, Suyoto \\ Universitas Atma Jaya Yogyakarta, Yogyakarta, Indonesia \\ amayaandridamaini@gmail.com
}

\begin{abstract}
Online transport service is currently popular in Indonesia. Not only provide ride-sharing service, but also other services such as food delivery, medicine delivery, and courier service. Ease of use and low cost make online transportation service more favored by consumers. However, this service has several disadvantages that cause inconvenience to the user until the occurrence of fraud action by the driver or the customer. Therefore identification of system deficiencies needs to be done to improve the security and convenience of customer and drivers of online transport services. This paper will analyze the problems of online transportation services applications through cases that have occurred and complaints of users of online transport applications. Through this analysis, we propose solutions to protect consumers and drivers for the security of transactions.
\end{abstract}

Keywords-Mobile Application, Online Transportation Application, Fraud Mitigation

\section{Introduction}

Current technological developments have penetrated into the online transport business [1][2]. The Internet has made it easier for people to connect with each other and the Internet-based service provides a drastic reduction in transaction costs between users and providers [3][4]. The growth of the internet, the globalization of trade, the advanced communication systems, challenges the internet technology in supplying the foundation of new business model, new business process, and new ways of marketing and distributing product, services and knowledge [5]. Just like how e-commerce grew rapidly, the development of mobile device is grown rapidly too, in the last decade many emerging Smartphone device influence the increase in mobile usage [6]. Internet users in Indonesia are increasing every year [7], this has led to an increase in the e-commerce market in Indonesia. Various online-based transportation services are also growing rapidly in Indonesia. Public transportation problems in Indonesia make an opportunity for online transport service providers. Online transport services such as Uber, Go-Jek, and Grab are increasingly attracting attention because of the convenience, low price, and ease of application use [8]. Fig. 1 shows the interface of some of online transport service apps. 
In April 2017, the Indonesian Consumers Institution Foundation conducted online surveys to users of online transport services involving 4,668 respondents[9]. One of the questions is the reasons Indonesian consumers choose or use online transport. In this survey respondents can choose more than one reason why they use online transport services. The result that can be seen in fig. 2 shows that the reasons are cheaper $(84.1 \%)$, faster $(81.9 \%)$, comfortable $(78.8 \%)$, and safe $(61.4 \%)$. Since the emergence of Uber as the first online transportation service in Indonesia [10], online transportation services began to grow in Indonesia, from outside providers to local start-ups are emerging to add to the competition of this online transportation business.

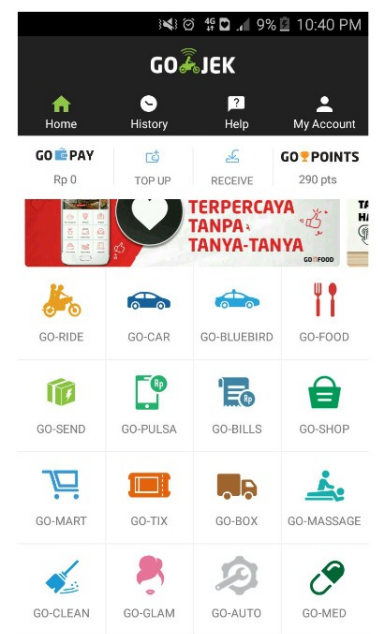

(a) Gojek

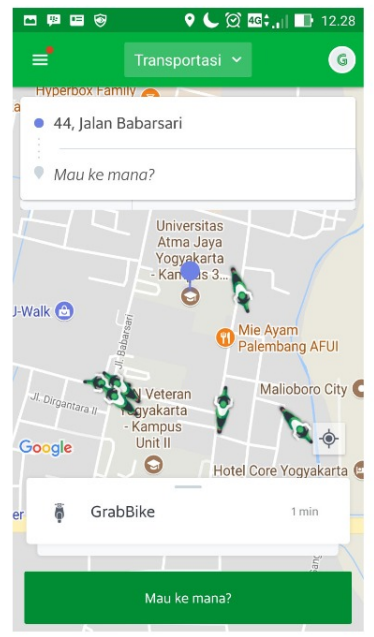

(b) Grab

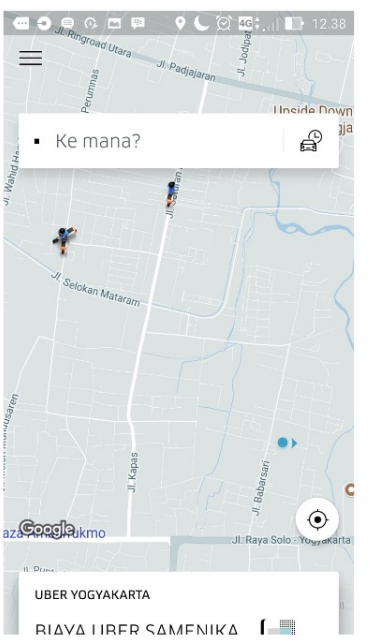

(c) Uber

Fig. 1. Interface of online transport services apps

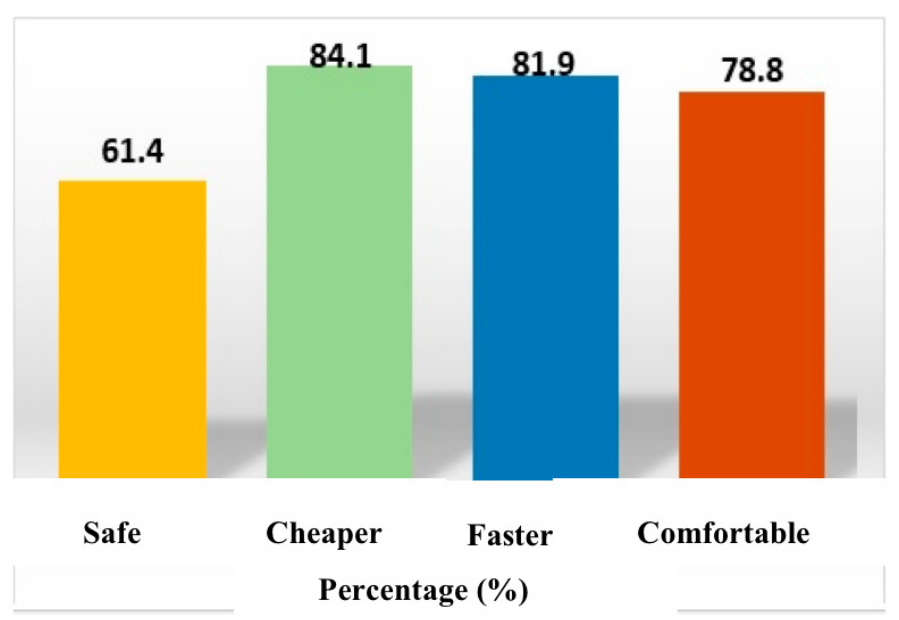

Fig. 2. Reasons consumers choose online transportation services 
Various online transport services compete for the market with the services and features and innovations offered. In addition to car-taxi or motorcycle-taxi services, the features that offered include food delivery service, delivery courier, shopping courier, etc.

Ease of use of online transport applications cannot be separated from the use of applied communication technology [11]. To use the online transport service, users simply need to download the application on the Smartphone and then place an order through the application. Users can know the identity of the driver through the application. Geo-location technology is used to calculate the distance and address, knowing the location of users and drivers [12].

Online transport service providers are constantly updating the application of online transport services to support user convenience, but there are still some issues that arise. The transaction security issues mostly resulting from the dishonesty of consumers or drivers by exploiting loopholes contained in the application.

\section{Material and Methods}

Although online transport services have been coming to Indonesia since 2010, this service has grown tremendously since 2015 when Go-Jek, one of Indonesia's local platforms launched a mobile app for motorcycle-taxi service[13] and become very popular in Indonesia[14]. From the Indonesian Consumers Foundation survey, three of the most popular online transportation applications (shown in fig. 3) are Go-Jek, Grab, and Uber. Gojek occupied the highest rating selected by consumers, $72.6 \%$; then Grab as much as $66,9 \%$ and Uber is used by $51 \%$ users. In this survey, the respondents can choose more than one application of online transport services they use. Online transport services in Indonesia use two types of vehicles, namely cars and motorcycles. Motorcycle-taxi which is generally called Ojek became the most popular service in Indonesia.

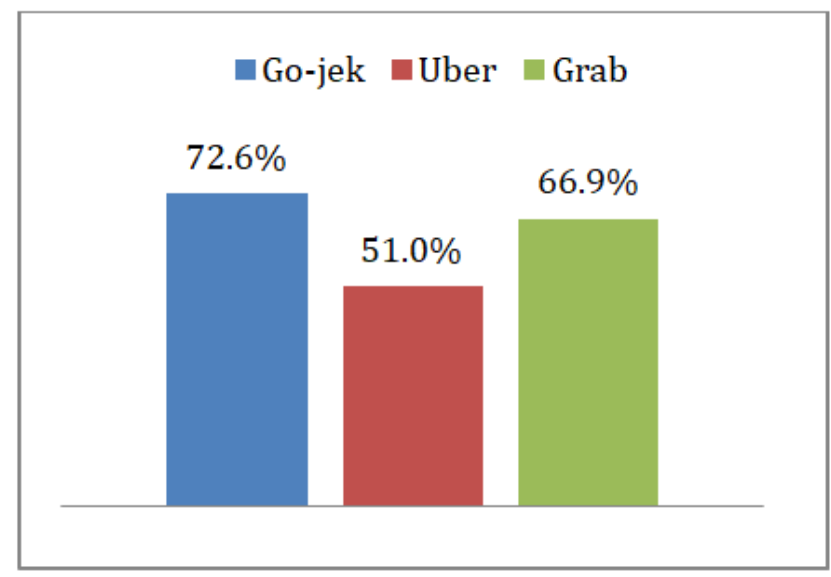

Fig. 3. Online Transportation Popularity in Indonesia 
Ojek is originally an unofficial public transport in Indonesia using motorbikes that are rented by way of passengers. Ojek service does have a faster mobility compared to other transportation services, that's why the people of Indonesia prefer this service. This is what drives platforms from outside Indonesia such as Grab and Uber [15] included motorcycle-taxi in the service. Although the beginning of the online transportation service to get a response pro and cons, now the service is increasingly accepted by the community. Local start-ups also develop many similar applications and compete in the online transport service business.

One of the things that make people interested in online motorcycle-taxi that is cheaper than the same services with car transportation. If generally the price determination was made by bargaining between passengers and motorcycle-taxi drivers, then with an online motorcycle taxi fares determined based on the distance and rush hour traffic. To attract the interest of consumers, the business of online transportation services also usually provides a specific promo for users of this service. To further provide convenience for consumers, the current online transportation service not only serves passenger shuttle. Other services offered include food delivery, delivery couriers, instant shopping services, and cinema ticket purchases. Even some of the online transportation service providers are now collaborating with conventional taxi companies, making it easier for people in choosing transportation services.

Trends in online transport services address public concerns about security guarantees in public transport because the customer can identify the identity of drivers to their contacts. Similarly, the driver can also know the identity of the customer he will pick up.

\subsection{Online Transportation Services Issues}

Various services and features are offered by online transport service providers to consumers and drivers generally to provide convenience and security in transportation services [16]. Apart from all the conveniences and conveniences that exist, the application of online transport services has several issues that reduce the sense of security in using this service. Some issues can even harm consumers and drivers. Here are some issues that appear in online transportation services.

Troubled GPS Network. Compared to other countries, internet speed in Indonesia tends to be slow and unstable [17]. The stability of the internet network is usually uneven; sometimes there are areas that are difficult to reach the $4 \mathrm{G}$ network. This affects the accuracy of GPS, while the online transportation services rely heavily on GPS [18] function for estimating fares, finding the nearby driver, notifying passengers and driver location, etc[8].

When the Internet network is unstable, then the GPS used by the user tends to be inaccurate in calculating the location[19]. This often leads to misunderstandings between drivers and customers. This inaccuracy can also affect the calculation of service tariffs that can result in financial losses to consumers or possibly drivers. If the internet network in Indonesia has a stable speed in all locations, then problems like this will not happen. 
Bad ratings and comments. To evaluate driver performance and customer satisfaction, the online transport service application features ratings and comments. With a rating system, users actively share their real experiences in the form of reviews and ratings [20]. Ratings and comments are given to the driver once the transaction is completed. The ratings and comments received by drivers are likely to have a positive impact on driver service to customers. The drivers strive to provide the best service to get a good rating from customers and avoid a low rating.

Low ratings can result in drivers getting suspended; the worst possibility is the termination of partnership with the online transport service providers, which means they cannot work as drivers on the platform. Sometimes there are some customers who make pranks by giving a high rating, but containing comments that dropped drivers. It turns out that it can also create suspend driver accounts that result in them not being able to use their accounts to work for a certain time. This rating system certainly harms the honest drivers if they get customers who give a subjective rating or even deliberately to attack drivers.

Cancellation of orders resulting in Financial loss. Order cancellation is often experienced by drivers or customers for certain reasons or conditions. If the order cancellation is done by agreement between the driver and the customer, this is not a problem. But sometimes there is a unilateral cancellation that resulted in losses for certain parties. One example of a unilateral cancellation is when the customer has made a shuttle booking and has been waiting at the pick-up location, but is suddenly notified through the application that the order was canceled by the driver. As a result, customers lose time because they have waited long enough. To reduce the order cancellation action by the driver, the platform provider lowers the driver rating if they over-order too often. To avoid this, drivers generally contact customers and ask customers to cancel orders through their apps.

Unilateral cancellation can not only be experienced by customers but also can happen to the driver. A shuttle service customer who feels they have waited too long often cancels their order in order to re-order, hoping that they will get a faster pickup driver.

Unilateral cancellation by the customer may result in financial losses to drivers. Generally, this case occurs in services that require drivers to buy something with their money first, such as food delivery service, cinema ticket purchase, or instant shopping service. As a result, drivers often get financial losses for ordering food and ready to deliver but suddenly customers cancel it.

Buy and sell driver account. To become an online transport service driver, it is necessary to apply to a provider of online transport platforms. Of course, there are conditions that must be met in order to become an online transport service driver. If you cannot meet these requirements, sometimes it is not uncommon for someone to buy an online transport driver account on the internet. Driver's account that is no longer used are now traded on the internet. By buying someone else's account, he assumes it will be able to avoid illegal sanctions against the provider of the platform because he uses someone else's driver account.

Often customers find that driver information such as photos and vehicle license plates are different from those found in reality. Illegally purchased driver account that 
contains the identity of others, this is already included in identity theft and at risk of being misused. Purchasing driver accounts with someone else's identity increases the risk of fraud cases involving online transport services.

Frauds. Fraud leads to losses for certain parties. The loss could even have an effect on the provider of the online transport platform. One example of fraud in the use of online transport applications is customer fraud against the pickup point. The customer puts a missed pick-up point from the actual location on purpose. Usually, this is done so that customers get a cheaper price.

There are many forms of frauds committed by some drivers. These frauds are generally done in order to get a high rating or get a lot of orders. The frauds are:

1. The driver sends a confirmation in the application that it has picked up the customer, but it is not, or the driver sends a confirmation of the ordered item or the food has been purchased and is ready to be delivered to the customer but not yet.

2. The driver performs a fictitious order using two mobile phones to place orders and receive orders.

3. Using auto-bid. this case occurs in the Go-Jek app. Auto-bid is an application modification that allows a driver to take incoming orders automatically without having to press a button on the application. This is detrimental to other drivers who do not use auto-bid because they are not fast enough in taking orders.

4. Using a fake Global Positioning System (GPS) application to deceive the system. This application will make it as if the driver is in a certain place, but in fact,he was somewhere else. This usually happens in crowded places. Impact, the order will flood from that location. It will even go faster than drivers that do not use this app even though they are in the same location.

Some cheats have led to criminal acts. One of them is the fraudsters calling or sending a text message to potential victims that there is an error sending the code so asking for potential victims to send a verification code. Another modus is to claim from the party of online transport service and offer fake promos. If a potential victim is off guard and follows it, then fraudsters can drain the balance of electronic wallets from user accounts.

Fraud can occur in goods delivery service. When the goods have been delivered destination, generally the driver to confirm the application, then the record tracking customer appears the delivery status of goods has been up. However, a dishonest driver will confirm even if the item has not reached the destination and then bring the customer away or ask for ransom if it is an important document

\subsection{Research Methods}

The purpose of this paper is to propose solutions to improve the security of the use of online transportation service applications from fraud. The approach used in this paper is based on literature studies and case studies. There are several steps taken in this study that can be seen in Fig. 4. 


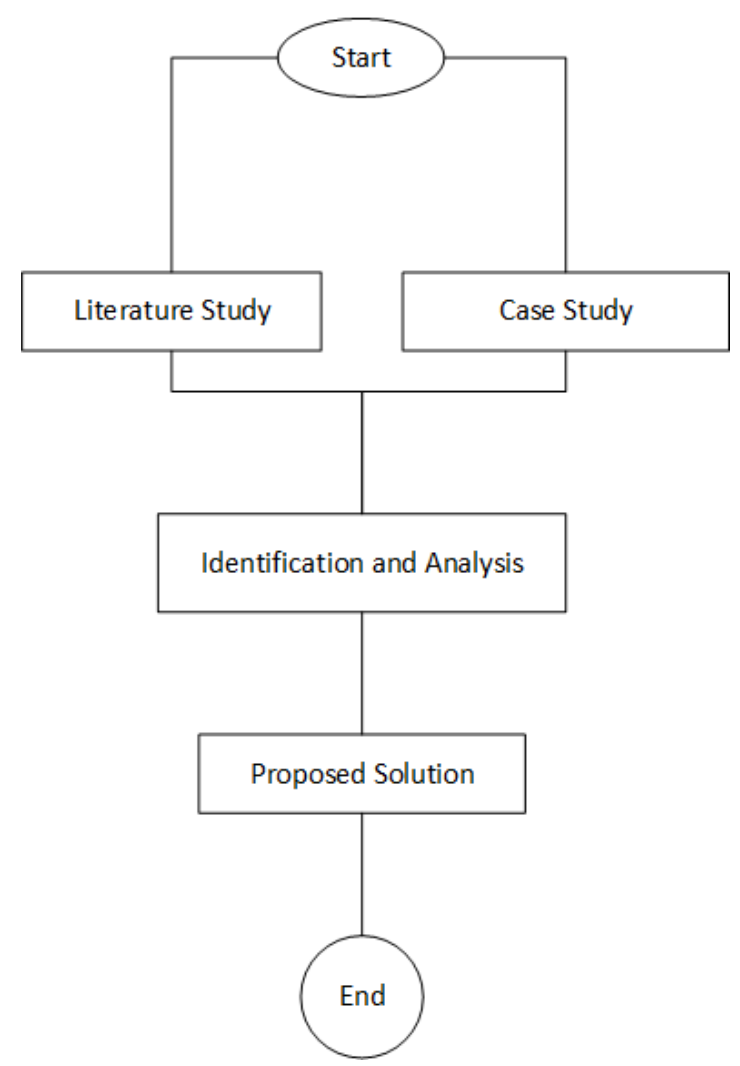

Fig. 4. Methods

This paper begins by reviewing issues of security and convenience in online transport services through news sites and complaints from users of online transport applications on social media. Together with this, the literature study was conducted by reviewing a number of articles, papers, and books related to online based transportation, and online fraud mitigation.

Based on the review, some important insights relating to the problem of application of online transportation services in Indonesia are summarized and identified. Once problems are identified, analysis can be done to find solutions to improve security and convenience in the use of online transport service applications.

After the identification and analysis step, the next step is to propose the solution according to the problem that has been identified and analyzed. Appropriate solutions are proposed and published in this paper. The proposed solution will be described in the form of a business process scheme that can be a solution to the problems found. 


\section{$3 \quad$ Result and Discussion}

\subsection{Identification and Analysis}

In recent years, mobile devices are increasingly being used for e-commerce. Ecommerce and technology have huge business revenue potential but tend to be prone to fraud such as identity theft and fraud [21].

As explained in the previous section, almost all the frauds are done by the driver to get a high rating or get a lot of orders. Apps that use ranking systems have a risk of rating manipulation. Ranking fraud has long caused great concern in the mobile Applications industry[22][23]. To improve the rating in a fast way then some drivers also use illegal ways like Auto-bid, fake order, using illegal additional apps, etc.

These problems can be solved from two sides, namely the rules and policy side of the application system. Currently, there are many policy rules applied and upgraded by the company provider of online transportation platform in order to improve the quality of service. The rules are generally the steps that must be done when receiving orders from users, as well as things that should not be done. The use of illegal application or application modification to improve driver performance is strictly prohibited. If the driver violates the rules, then they will receive a penalty, a penalty that often imposed is suspend the account. When the driver gets suspended, the driver cannot accept orders within a certain time period depending on the severity of the violation committed. Account suspend accounts can also occur in drivers that resist many orders in one minute.

Modifying apps by using an auto-bid is illegal and is prohibited since it is unfair to drivers who do not use auto-bids. To avoid auto-bid, there is a timer that applies to the application to calculate the speed of the driver pressing the receive button. Since humans are unlikely to push buttons at a certain speed, then if it is too fast, it is likely they are using auto-bid, so it becomes a consideration by the provider company to crack down on user drivers. But as time goes by, Go-Jek has allowed its official use by adding Auto-bid feature in application version 1.0.86, where this feature can be activated/disabled and adjusted according to driver's desire. But the Go-Jek also provides a requirement for its use, which must be responsible for jobs obtained through the feature with the obligatory to implement it.

For the case of order cancellation, Uber has enforced the rules that prevent customers from canceling orders. The customer will be charged a loss if canceling the order and the cost of the loss will be received by the driver. However, this rule only applies to shuttle service. This rule may be adopted for food ordering services or other services that require drivers to use their money first to pay. For more details, Fig. 5 shows the process that occurs when the ordering transactions food. 


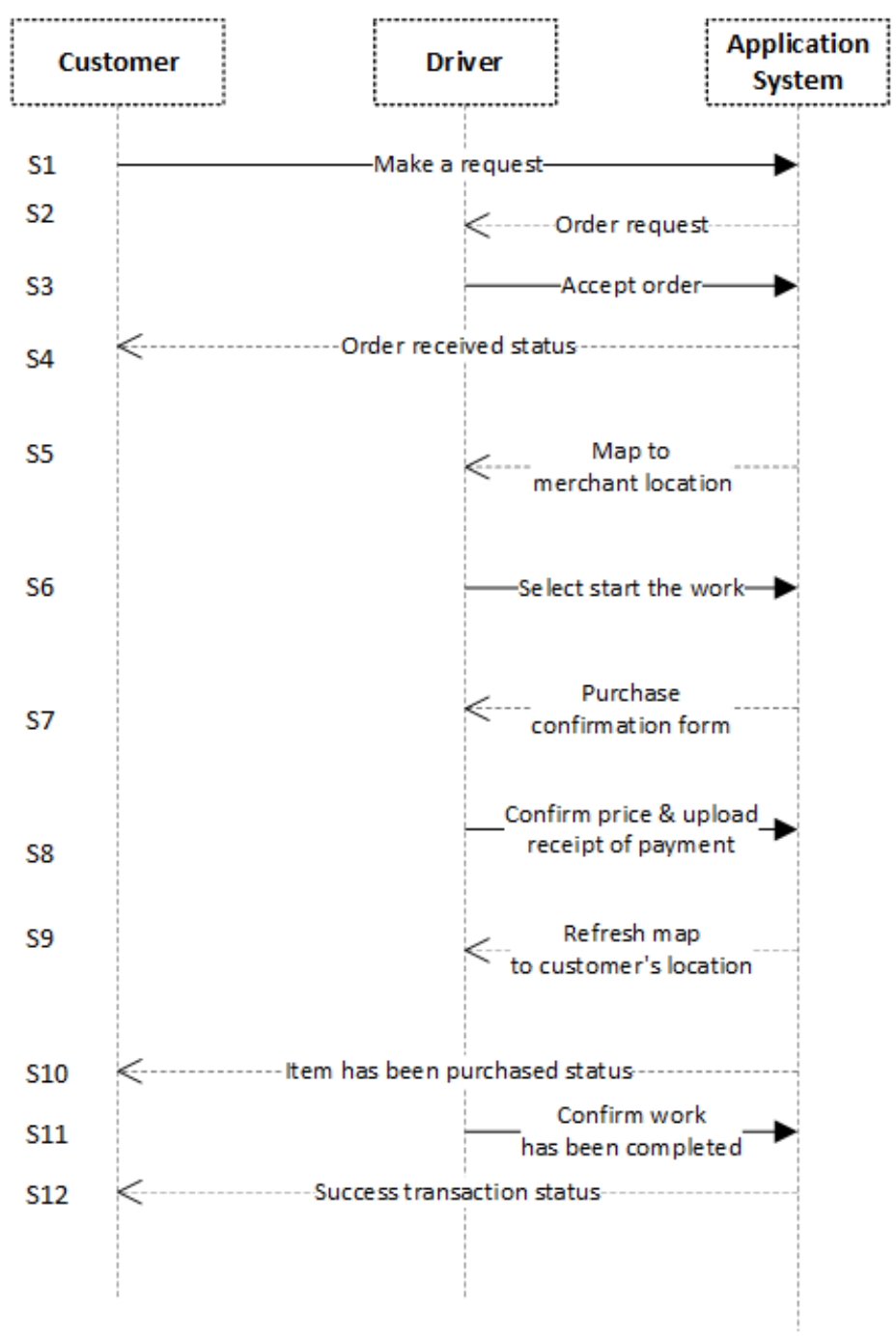

Fig. 5. Food Delivery Service Transaction Scheme

There are 12 steps in the process of ordering food service transactions. Descriptions of the steps are listed in table 1. This scheme occurs under normal conditions, where no order cancellation occurs. If there is a cancellation order by the customer when the process is being executed, then the transaction will end. This will result in a loss to the driver if he has already purchased the ordered item. It would be easy for the driver to ask the company to compensate for the loss if he had time to confirm the purchase of the item (step S8) on the application. If you have not made a purchase confirmation, it will take a long process to get the compensation. It is also certainly detrimental to the service provider companies because they have to pay the losses experienced by drivers. 
Paper-Fraud Crime Mitigation of Mobile Application Users for Online Transportation

Table 1. Table 1. Steps of Food Delivery Service Transaction Scheme

\begin{tabular}{|c|l|}
\hline Steps & \multicolumn{1}{|c|}{ Description } \\
\hline S1 & Customer make an order request \\
\hline S2 & Application system sends order request to driver \\
\hline S3 & Driver accept the order \\
\hline S4 & The System sends status to the customer that the order being received \\
\hline S5 & System shows map to merchant location \\
\hline S6 & Driver select start the work after purchased the items ordered \\
\hline S7 & Application system shows confirmation form \\
\hline S8 & Driver input the price to confirm and upload the payment receipt picture \\
\hline S9 & System refresh the map to customer's location \\
\hline S10 & $\begin{array}{l}\text { The System sends status to the customer that the item has been purchased and being delivered } \\
\text { to the customer's location. }\end{array}$ \\
\hline S11 & Driver confirm that work has been completed after the item is delivered \\
\hline S12 & System sends success transaction status to customer \\
\hline
\end{tabular}

Fig. 6 shows ride order transaction in online transportation service. There are 10 steps in this scheme. Detailed steps can be seen in table 2. Steps shown in fig. 6 is an ideal situation that should occur when the transaction ordering service motorcycletaxi or car-taxi. Drivers must select the "Start the work" button when they have met with the customer and ready to deliver to the destination. But in fact, there are some dishonest drivers by sending confirmation that they have picked up the customer, even though they have not been on location. This can happen because the driver can choose a pickup confirmation button wherever they are, even if they are not already in the location.

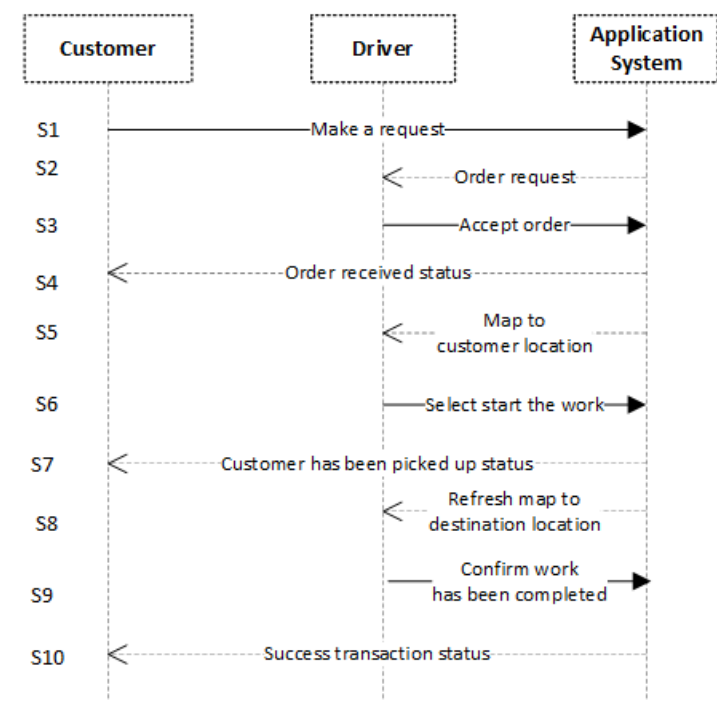

Fig. 6. Ride Service Transaction Scheme 
Paper-Fraud Crime Mitigation of Mobile Application Users for Online Transportation

Table 2. Steps Ride Service Transaction Scheme

\begin{tabular}{|c|l|}
\hline Steps & \\
\hline S1 & Customer make an order request \\
\hline S2 & Application system sends order request to driver \\
\hline S3 & Driver accept the order \\
\hline S4 & The System sends status to the customer that the order being received \\
\hline S5 & System shows map to customer location \\
\hline S6 & Driver select start the work after meeting the customer \\
\hline S7 & Application system shows picked up status \\
\hline S8 & System refresh the map to destination location \\
\hline S9 & Driver confirm that work has been completed after riding the customer to the destination \\
\hline S10 & System sends success transaction status to customer \\
\hline
\end{tabular}

\subsection{Proposed Solution}

To solve the problem of the ordering transaction, we propose a solution adopted from Uber, which imposes a loss on the customer canceling the order. Fig. 7 and table 3 show the scheme with the proposed solution when the ordering transaction is canceled.

When a customer cancels an order when an item has been purchased, the fee will be charged to the customer, provided that the driver has passed the S8 step. However, if the driver has not yet confirmed the purchase of the item, the driver can still make a reimbursement request by uploading the drawing of the receipt of payment. After that, the system will process the request and charge the loss on the customer's electronic wallet. Requests for compensation sent to the system will be acted upon by the service provider company for consideration whether it is accepted or rejected.

Table 3. Steps of Food Delivery transaction with proposed solution

\begin{tabular}{|c|l|}
\hline Steps & \multicolumn{1}{|c|}{ Description } \\
\hline S1 & Customer make an order request \\
\hline S2 & Application system sends order request to driver \\
\hline S3 & Driver accept the order \\
\hline S4 & The System sends status to the customer that the order being received \\
\hline S5 & System shows map to merchant location \\
\hline S6 & Driver select start the work after purchased the items ordered \\
\hline S7 & Customer cancels the order \\
\hline S8 & System sends order canceled notification \\
\hline S9 & Driver select the compensation request \\
\hline S10 & System send compensation request form \\
\hline S11 & Driver sends compensation request after filling the form \\
\hline S12 & $\begin{array}{l}\text { System process the request and charging the compensation fee from customer's electronic } \\
\text { wallet }\end{array}$ \\
\hline S13 & System sends compensation notification \\
\hline
\end{tabular}




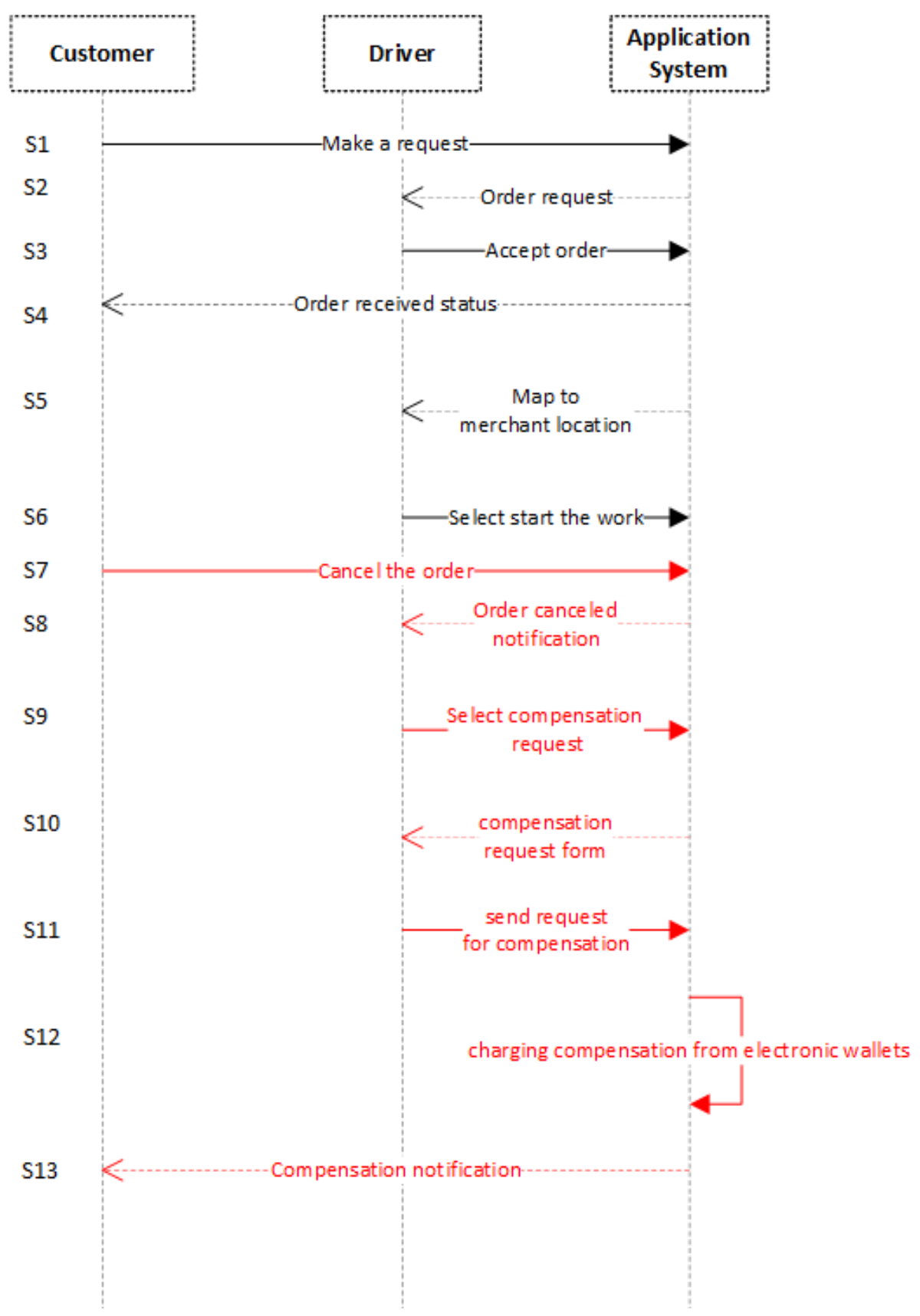

Fig. 7. Food Delivery Transaction with proposed solution

By applying this scheme to the issue of order cancellation by the customer, that is by charging the cost of loss to the customer. This is considered fair enough for drivers 
and customers. To apply this scheme, payments must be made through an electronic wallet so that the cost of loss can be deducted from the customer's electronic wallet automatically. Thus, this scheme cannot be applied if payment is made in cash.

To mitigate the driver's dishonesty during the customer's pickup confirmation, we propose a solution by giving a change to the S6 step of the ride service transaction scheme, by enabling the pickup confirmation button only when the driver is located a few meters from the destination. The driver can only confirm the customer has been picked up and successful transactions when they within a certain distance from the destination location, then close the opportunity for drivers to commit fraud. Thus, the customer can receive correct information from the driver. The schemes that proposed can solve fraud problems that arise in the online transport services.

\section{Conclusion}

In the online transport service, the convenience and security of transactions between customers and drivers is very important. Although regulation and policy are applied to avoid fraud, security steps from the application side need to be done to close the chance of user to cheat. The proposed food delivery service transaction scheme can provide a solution to avoid losses to drivers and online transport service providers. This scheme can also avoid fictitious orders by irresponsible customers.

Simple changes that proposed in the ride service transaction process can mitigate the dishonesty committed by the driver to the customer. Both of these proposed schemes we can provide solutions to enhance the convenience and security oftransactions of online transport services.

\section{$5 \quad$ References}

[1] A. B. Traum, "Expanding Innovation Law: Information Technology and Insurance," J. Internet Law, vol. 22, no. 1, pp. 12-22, 2016.

[2] L. W. Munnich and M. Iacono, "Competitive industry clusters and transportation in Minnesota," Compet. Rev., vol. 26, no. 1, pp. 25-40, 2016. https://doi.org/10.1108/CR-032015-0018

[3] A. H. Henten and I. M. Windekilde, "Transaction costs and the sharing economy," Info, vol. 18 , no. 1, pp. 1-15, 2016. https://doi.org/10.1108/info-09-2015-0044

[4] T. Teubner and C. M. Flath, "The Economics of Multi-Hop Ride Sharing: Creating New Mobility Networks Through IS,” Bus. Inf. Syst. Eng., vol. 57, no. 5, pp. 311-324, 2015. https://doi.org/10.1007/s12599-015-0396-y

[5] M. S. Al-Ani, "Next Generation Digital Commerce Technologies," Int. J. Interact. Mob. Technol., vol. 3, no. 2, pp. 58-62, 2009. https://doi.org/10.3991/ijim.v3i2.655

[6] B. Robi' in, L. A. Wardana, and S. Suyoto, "New Solutions for Instant Payment Problems in Indonesia," Int. J. Adv. Sci. Eng. Inf. Technol., vol. 7, no. 4, p. 1191, Aug. 2017. https://doi.org/10.18517/ijaseit.7.4.2221

[7] A. of I. I. S. Providers, "Association of Indonesian Internet Service Providers." [Online]. Available: https://apjii.or.id/content/read/39/27/profil-pengguna-internet-indonesia-2014. [Accessed: 02-Oct-2017]. 
[8] S. Guo, Y. Liu, K. Xu, and D. M. Chiu, "Understanding passenger reaction to dynamic prices in ride-on-demand service," 2017 IEEE Int. Conf. Pervasive Comput. Commun. Work. PerCom Work. 2017, pp. 42-45, 2017.

[9] Indonesian Consumer Institutions Foundation, "Consumer News: Online Transportation; Friend or Foe?," 2017. [Online]. Available: http://ylki.or.id/2017/07/warta-konsumentransportasi-online-kawan-atau-lawan/. [Accessed: 12-Nov-2017].

[10] "Reap Controversy, Here's The Beginning of Online Taxi Story in Indonesia | Money.id." [Online]. Available: https://www.money.id/digital/tuai-kontroversi-begini-awal-mulakisah-taksi-online-di-indonesia-160316g/grabcar-dan-uber.html. [Accessed: 22-Oct-2017].

[11] E. Turban, J. Outland, D. King, J. K. Lee, T.-P. Liang, and D. C. Turban, "Mobile Commerce and the Internet of Things," Springer, Cham, 2018, pp. 205-248.

[12] C. Tossell, P. Kortum, C. Shepard, A. Rahmati, and L. Zhong, International journal of interactive mobile technologies : iJIM., vol. 9, no. 2. Kassel University Press, 2015.

[13] E. Turban, J. Outland, D. King, J. K. Lee, T.-P. Liang, and D. C. Turban, "Mobile Commerce and the Internet of Things," in 2015 International Conference on Information Technology Systems and Innovation, ICITSI 2015 - Proceedings, 2018, pp. 205-248.

[14] P. W. Handayani and D. F. Alaika, "A model of information sharing process on social media," in 2017 International Conference on Research and Innovation in Information Systems (ICRIIS), 2017, pp. 1-6.

[15] "Uber Brings Motorcycle Hailing Service to Indonesia - ProQuest," Wall Street Journal (Online), New York, 14-Apr-2016.

[16] G. Dai, J. Huang, S. M. Wambura, and H. Sun, "A balanced assignment mechanism for online taxi recommendation," in Proceedings - 18th IEEE International Conference on Mobile Data Management, MDM 2017, 2017, pp. 102-111. https://doi.org/10.1109/ MDM.2017.23

[17] "Internet in Indonesia: Internet Connection Speed Remains Weak | Indonesia Investments." [Online]. Available: https://www.indonesia-investments.com/news/todaysheadlines/internet-in-indonesia-internet-connection-speed-remains-weak/item2477? [Accessed: 23-Oct-2017].

[18] R. Shen, T. Terada, and M. Tsukamoto, "A method for controlling crowd flow by changing recommender information on navigation application," Int. J. Pervasive Comput. Commun., vol. 12, no. 1, pp. 87-106, 2016.

[19] W. Chen, "Technical Improvements on Mobile App Based Taxi Dispatching System," no. Csss, pp. 281-284, 2014.

[20] M. Khalid, U. Shehzaib, and M. Asif, "A Case of Mobile App Reviews as a Crowdsource," Inf. Eng. Electron. Bus., vol. 5, no. 5, pp. 39-47, 2015. https://doi.org/10.5815/ijieeb.2015.05.06

[21] G. Carmi and S. Y. Segal, "Mobile Security: a Review of New Advanced Technologies to Detect and Prevent E - Payment Mobile Frauds," Int. J. Comput. Syst., vol. 292, no. 4, pp. 2394-1065, 2394.

[22] H. Zhu, H. Xiong, Y. Ge, and E. Chen, "Discovery of ranking fraud for mobile apps," IEEE Trans. Knowl. Data Eng., vol. 27, no. 1, pp. 74-87, Jan. 2015. https://doi.org/10.1109/TKDE.2014.2320733

[23] M. Zende and P. Gupta, "Ranking Fraud and Fake Reviews Detection for Mobile Apps," Int. J. Adv. Res. Comput. Sci., vol. 7, no. 3, pp. 240-243, 2016. 


\section{Authors}

Amaya Andri Damaini is a Master of Informatics Engineering Student in Mobile Computing major at Universitas Atma Jaya Yogyakarta, Yogyakarta, Indonesia. She got her bachelor degree from Sekolah Tinggi Manajemen Informatika dan Komputer Palangkaraya in 2015. Her research interests are mobile application and pattern recognition.

Ginanjar Setyo Nugroho is a Master of Informatics Engineering Student at Universitas Atma Jaya Yogyakarta, Yogyakarta, Indonesia. He has more than 2 years as primary school teacher, junior high school teacher, and senior high school teacher. He received his bachelor degree in 2015 from Duta Wacana Christian University. His research interests are digital image processing, mobile application and artificial intelligence.

Suyoto is a Professor in Department of Informatics Engineering at Universitas Atma Jaya Yogyakarta, Indonesia. He has more than seventeen years of teaching experience. He received his $\mathrm{PhD}$ in 2000 from the National University of Malaysia, Malaysia. His research interests are multimedia, computer graphics, visualization, mobile application and artificial intelligence.

Article submitted 04 December 2017. Resubmitted 26 April 2018. Final acceptance 08 May 2018. Final version published as submitted by the authors. 